\title{
BUILDING INFORMATION MODELLING IN OPERATIONS OF MAINTENANCE AT THE UNIVERSITY OF ALICANTE
}

\author{
ANTONIO GALIANO-GARRIGÓS ${ }^{1}$ \& MARÍA DOLORES ANDÚJAR-MONTOYA ${ }^{2}$ \\ ${ }^{1}$ Department of Architectural Constructions, University of Alicante, Spain. \\ ${ }^{2}$ Department of Building Sciences and Urbanism, University of Alicante, Spain.
}

\begin{abstract}
The benefits derived from the use of building information Modeling (BIM) methodologies are a current issue in the field of research in both design and construction phase. However, the profits achieved in the maintenance stage are still an almost unexplored issue. This fact is especially relevant in public organizations, in particular on university campuses where the building assets are a value added service that must maintain their quality. In this connection, this paper aims to restructure the current maintenance operations at Alicante University and focus them towards BIM environments. It identifies the current building maintenance process on campus, determining the problems it faces since an incident occurs until it resolves. To this end, the research methodology includes semi structured surveys, interviews and benchmarking sessions with technical office staff, managers and maintenance workers at the University of Alicante together with relevant external stakeholders. Consequently, all the information obtained will enable a better procedure based on BIM for improving both preventive and corrective maintenance. The study case is focused on the renovation of the building Former Faculty of Education at The University of Alicante and the results confirm the potential of implementing BIM on campus through a more accurate access to information that optimizes and speeds up the maintenance process.
\end{abstract}

Keywords: building information modelling, BIM, building maintenance.

\section{INTRODUCTION}

The construction sector is immersed in a process of reinvention. As it was stated in AndujarMontoya et al. [1], the current social and economic-financial context - characterized by higher customer expectations, global competition, market fragmentation, technological changes and scarce funding - leads traditional models to failure. Undefined projects and miss-coordination during the construction are in the way to become obsolete. As a consequence, a change of mentality is taking place in order to improve quality and productivity of the industry.

One of the most transcendental changes is the adoption of the building information modeling (hereinafter BIM) paradigm. BIM is an emerging technology that provides an integrated solution for managing construction projects throughout its life cycle, i.e. acting as a backbone from the definition of project objectives to the fulfilment of its useful life (Fig. 1).

This BIM backbone is a digital representation of the building process that allows the exchange and interoperability of information in digital format. Several researches have been focused on the acceptance and implementation of BIM in the sector [2-6].

Likewise, BIM is being progressively introduced by many designers and engineers in the design phase and large construction companies in the construction management. Above all, the administration must adapt its procedures due to the publication by the European Union (EU) of the European Directive for Public Procurement, which promotes the use of electronic tools like BIM in construction projects financed by EU public funds. But although some countries like The United Kingdom, Denmark, Netherlands, Norway and Finland already 


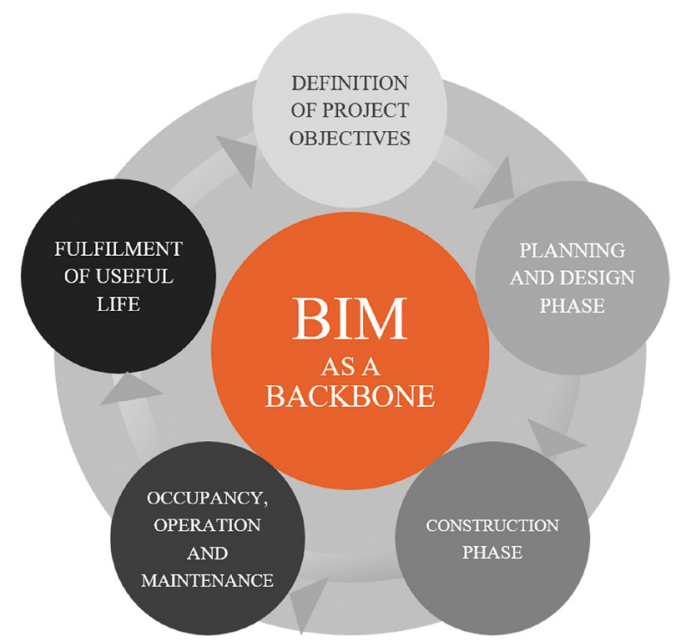

Figure 1: BIM paradigm as a backbone of construction projects life cycle.

require BIM for public works, in Spain the awareness and a gradual adoption among construction stakeholders is currently spreading [7], the implementation has not started for the administration and it is still at an initial stage above all for SMEs.

Furthermore, the use of BIM is still a challenge in the Spanish construction sector. The lack of knowledge about the later use and interaction with the model in the rest of the life cycle phases, such as the operation and maintenance phase, make the profits achieved in that stage an almost unexplored issue. In this connection, globally, facility management is the least known field within the building process life cycle. It consists of the exploitation phase of the finished building. However, its importance is being lately increased in the sector in an exponential way [8]. This is not surprising considering that in terms of time and cost, only the operation and maintenance phase expands to over $60 \%-80 \%$ of an architectural project life cycle [9-11].

According to the above, facility management is especially relevant in public organizations - in particular on university campuses characterized by a tight financing - where the buildings assets are a value-added service that must maintain their quality.

Within this framework, this paper aims to restructure the current maintenance operations at Alicante University and focus them towards BIM environments.

The remainder of the paper is organized as follows: Section 2 describes the state of the art about the use of BIM for maintenance operations, Section 3 explains the design of the research and the proposed theoretical framework for a more efficient maintenance process, Section 4 shows the experimentation carried out through a study case of the Former Faculty of Education building at the University of Alicante, and finally, in Section 5 conclusions are exposed.

\section{STATE OF THE ART: BIM FOR OPERATIONS AND MAINTENANCE}

As it was stated in the previous section, both Facility Management in finished buildings and the adoption of the BIM paradigm are becoming increasingly relevant. Some studies have 
focused on the exploration of how they complement each other and the potential benefits of the synergy between them, as well as risks and barriers to its implementation and future trends $[2,4,12,13]$.

Although Chen and Luo [14] and Bynum et al. [15] agree that it is frequently emphasized the potential of BIM to support a transformation of the processes of design and construction, it is confirmed that BIM is most often used in the early stages with progressively less use in the latter stages as Eadie et al. [16] confirm. Most of the limited research found about BIM in Facility Management activities is related to integration and storage $[11,17]$ and visualization [18-22], as it is shown next.

In this sense, Akcamete et al. [11] show the benefits of having As-is facility information, as well as the integration and storage in BIM of all the maintenance and repair activities performed. Some of these reported benefits are the determination of the deterioration causes of a building, among others. Similarly, Motamedi et al. [17] present the inspection and maintenance information through a computerized management system integrated with BIM for visual analysis. The system presented allows the creation of visualizations for finding root causes of failures in buildings.

Other related works, Chen and Wang [18], Liu and Issa [19] and Lin and Su [20], have highlighted three-dimensional visualization as a fundamental element in some Facility Management activities by the use of an accurate geometry and real data to support the maintenance service of facilities.

Furthermore, it has been analysed some works - Motawa and Almarshad [21], Porwal and Hewage [22] - that relate specifically Facility Management practices to the use of BIM in public organizations.

And finally, Wang et al. [9] develop a framework that integrates Facility Management and BIM from an early stage in the design phase to minimize the efforts for maintenance during the operational phase of facilities.

The literature previously specified confirms the importance of adopting BIM together with Facility Management from an early stage. This fact is especially important in complex buildings usually belonging to corporations and public organisations, such as universities, to ensure the delivery of high quality services to citizens, in public buildings that are increasingly complex and sophisticated.

\section{RESEARCH DESIGN}

\subsection{Current building maintenance process at campus}

The campus of the University of Alicante is located in San Vicente del Raspeig. With a current area of about one million square meters and under an important expansion process, it has been built on an old military airfield. It includes several green spaces and 54 buildings - new construction buildings as well as the reuse of the pavilions of the old aerodrome that date from 1930. The size of the university makes necessary an Infrastructure and Service Unit to ensure the right functioning of the infrastructure and the operability of outsourced services in the campus. This unit is divided into two branches, Maintenance Office and Technical Office.

The starting point of this research is the analysis of the current maintenance process. In collaboration with the Infrastructures and Services Unit, it has been determined the procedure (Fig. 2) according to the information gathered through interviews with staff of the Technical Office sub-unit. 
As it is shown in Figure 2, the process starts when a user requests a service through the Campus Virtual (campus intranet), the interface request basic information about user personal data, location where service is required, contact person, service required and urgency. Once the request is sent, the report is checked by the Bureau of Maintenance and Services. Daily and simply maintenance tasks are developed through a frame contract that yearly it is commissioned to a maintenance company. Depending on the complexity of the service required and whether it is within the frame contract of maintenance, the authorized maintenance parts are sent to Manttest, which is the software currently used to control the maintenance of the university by the commissioned maintenance company. Then, the project info has to be searched in the departmental files. After that, it is generated the work order which is automatically sent to the corresponding trades of masonry, electricity, plumbing, etc. to fix the problem.

At the same time if a project is not considered within the frame contract with the maintenance company or it cannot be solved by the maintenance company, because of complexity, specificity or work volume, then, a special procedure is needed. This procedure includes a project commission which follows the next steps: approval start studies, technical reports and concretion of needs, approval technical reports, estimation of cost and fees and the final approval of the Commission of Infrastructure before the beginning of works. When this happens, the technicians from the Technical Office have to look for the project info in the departmental files and check if the information is correct, check if the project info matches with what actually was built. Regarding this, it is important to emphasise that Spanish Regulation allow the inclusion of another materials with same properties in construction

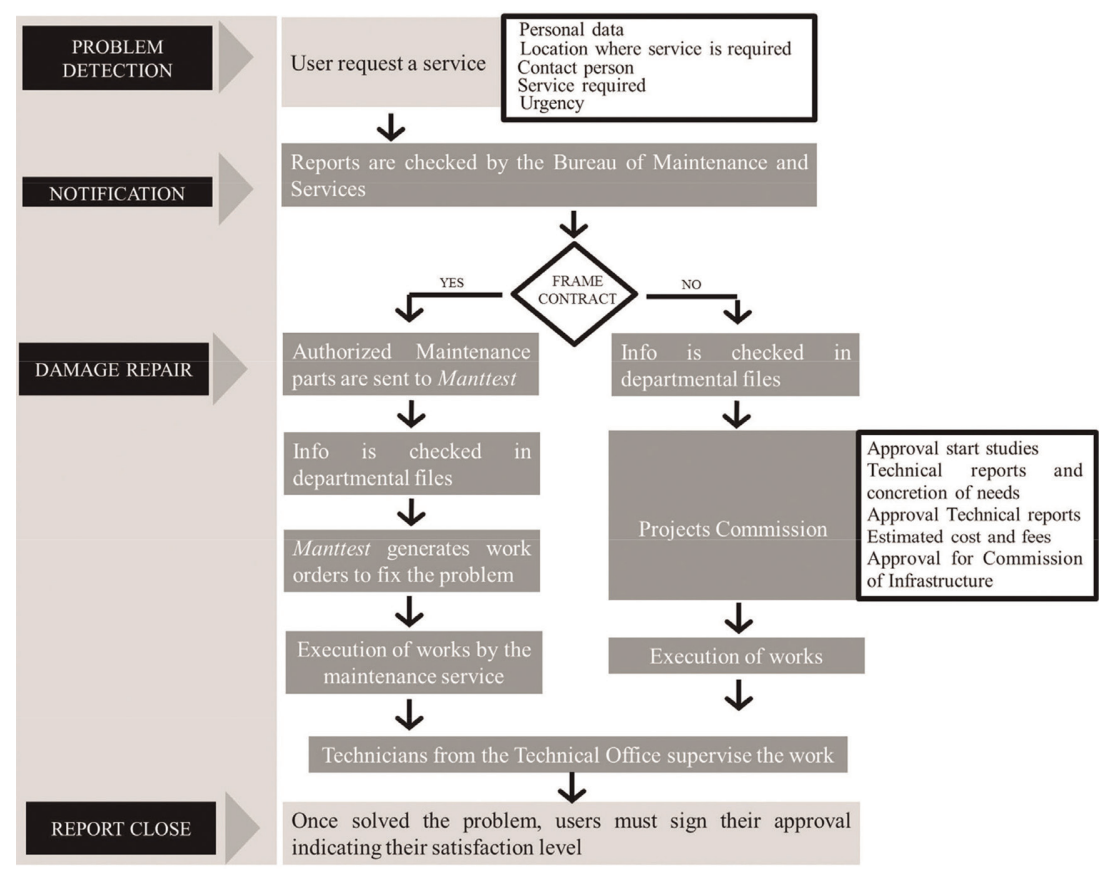

Figure 2: Current maintenance process of the Infrastructures and Services Unit. 
projects. Once information is verified, it is sent to the commissioned construction company.

In both situations, the process ends once the incidence is solved and the user signs its approval indicating its satisfaction level. All this previous process shows that the control software used in the process allows the Infrastructures and Services Unit getting limited information of the maintenance process, such as user satisfaction, the time of attention of the request. Furthermore, the current process is not able to achieve a higher performance to optimize resources and to have a greater control over the maintenance of assets. Especially, if we take into account the large size of the campus of the University of Alicante and the dispersion of its buildings in it.

\subsection{Benchmarking sessions about maintenance process at campus}

After identifying the maintenance process through interviews with technical office staff, there were carried out surveys and benchmarking sessions with managers and maintenance workers at the University of Alicante and other relevant external stakeholders. These surveys and benchmarking sessions allowed us to know the unmet needs and weaknesses of the current procedure. All the problems detected were related to limitations in the process and unused or underutilized resources. The surveys and benchmarking sessions dealt with eight topics areas:

Time control to repair the problem or incident,

Cost control to repair the problem or incident,

Necessary documents used during the operations and maintenance of buildings,

Storage of information,

Record changes made in the buildings at the campus,

Effectiveness losses due to management work done by human labour,

The future of maintenance in public organisations,

Other relevant issues.

\subsection{Limitations identified in maintenance process at campus}

After the identification and analysis of the entire procedure, some weaknesses have been detected. The first limitation detected is efficiency. Due to the large size of the campus and the building dispersion, the level of efficiency and productivity are reduced due to activities that do not add value to the service, such as movement of the maintenance service operators along the campus.

Furthermore, the high number of buildings protected on campus - because they have architectural awards or just because of architect's own requirement - make it necessary to foresee that project info must be searched in the departmental files and verified, in addition to inform maintenance operators about the singularity of the building. All this requires manual work which wastes time and resources, as well as adding risk of human errors in the process.

Likewise, the current system used prevents a more efficient preventive maintenance of the university resources, accessible by all agents involved in the process. Currently, the information control of the preventive maintenance it is managed by the maintenance service through the Manttest software, where data of the manufacturers is introduced manually. In addition, this preventive maintenance is only carried out in certain equipment and not in the entire university heritage. 


\subsection{Proposal of a theoretical framework for a more efficient maintenance process}

The analysis of previous weaknesses leads us to a refinement and reconceptualization of the current maintenance process. As it is shown in Figure 3, this work presents a theoretical framework based on BIM methodologies together with emerging technologies, such as, smart sensors technologies, personal devices and internet of things (hereinafter IoT's) paradigm to integrate and automate the current maintenance process.

This synergy will improve the efficiency of the maintenance process. While the BIM paradigm allows the integration and centralization of computerized information of all the campus' assets, the emerging technologies allow the detection, positioning and control of those elements.

In this sense, BIM allows the standardization and codification of all the information concerning the university heritage. This centralization of information and the storage of changes enable obtaining an As-built model, adapting the building log book into a real updated document in a single file, reliable and exportable. Moreover, BIM allows preparing maintenance plans from predictive data, as well as saving supply companies information and service history. This fact also allows an efficient and centralized management of purchases.

All these benefits of BIM are enhanced by being included within a theoretical framework that automates the process avoiding human errors and loss of information. This automation is achieved through the use of smarts sensors such as controllers and global positioning system (hereinafter GPS) technologies to detect and control service failures automatically.

Furthermore, all the necessary information for the optimal operation of the maintenance process is accessible from any place and any device due to the incorporation of personal devices and IoT's. This ubiquity of information is especially relevant on campus due to its extent and the dispersion of its buildings.

So, the next figure (Fig. 4) shows the refinement and reconceptualization of the current maintenance process through a theoretical framework based on BIM methodologies together with smart sensors, personal devices and IoT's.

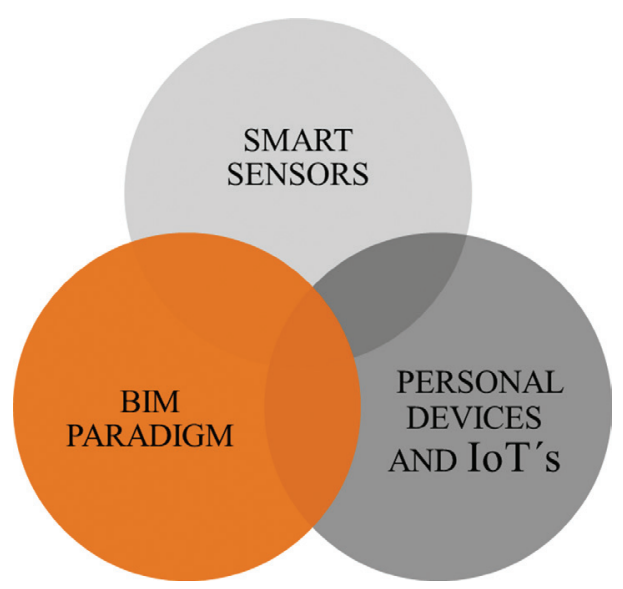

Figure 3: Paradigms and technologies included in the theoretical framework of maintenance process. 


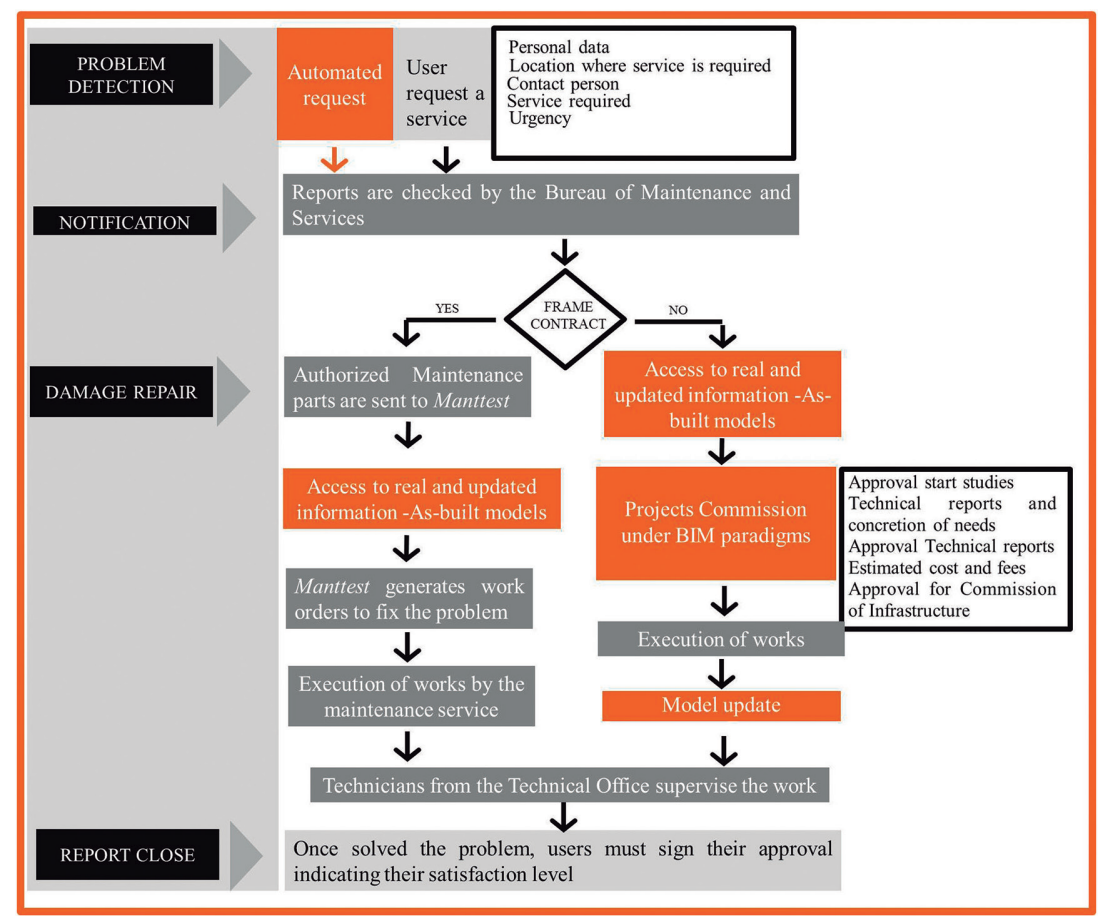

Figure 4: Theoretical framework that highlights in orange where BIM methodologies, smart sensors, personal devices and IoT's are used.

\section{STUDY CASE: THE RENOVATION OF THE FORMER FACULTY OF EDUCATION BUILDING AT THE UNIVERSITY OF ALICANTE}

The study case is focused on the renovation of the Former Faculty of Education building at the University of Alicante, verifying the part centred in the BIM paradigm of the proposed theoretical framework. The next figures (Figs 5-8) confirm the potential of implementing $\mathrm{BIM}$ on campus through a more accurate access to information that optimizes and speeds up the maintenance process.

These figures show the information that an As-built model includes. In a broader way it is possible to know the GIS UA code, the number of building, the floor, the space number, the geolocation and the area, as well as the person associated to this space. In a specific way, it is possible to know the inventory of elements associated to that space, such as windows, door, lamps, furniture etc. (Fig. 5).

This information is easily accessible from any device and any place through IoT's and personal devices like tablets or smartphones. Therefore, it avoids unnecessary movements of maintenance operators along the campus. Likewise, the ubiquity of the information integrates all the stakeholders, i.e. technicians from the Technical Office, maintenance service managers, maintenance service operators, Office of the Vice President of Campus and Technology and other construction companies or agents that may participate on the project. This integration of information and people will avoid misunderstandings and human errors in the verification of the project information in the departmental files. 


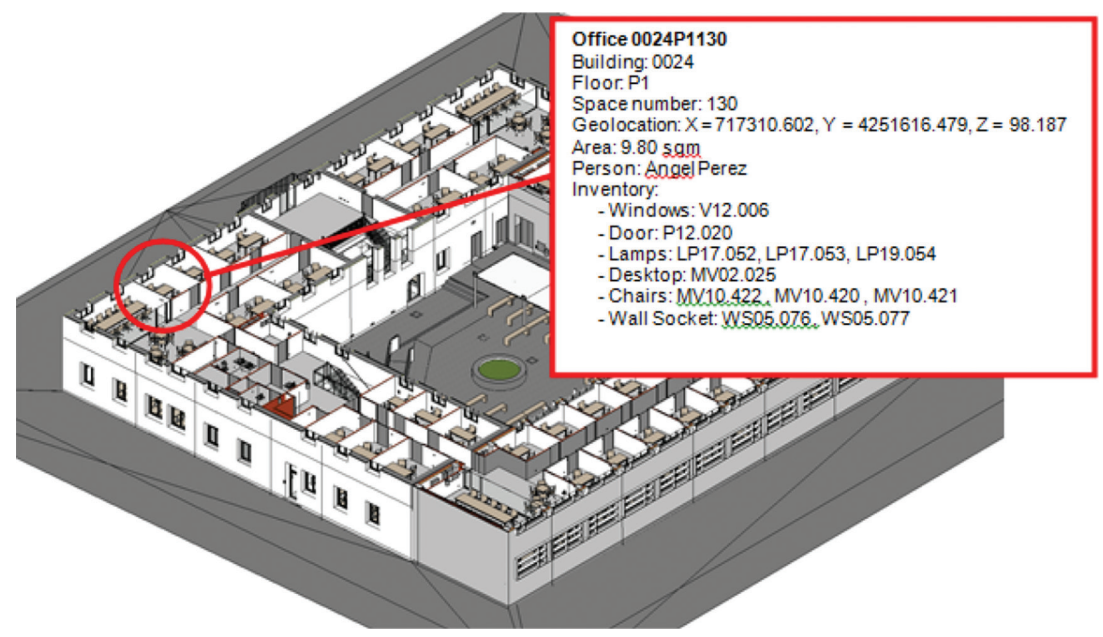

Figure 5: Data integration of the space and its associated elements.

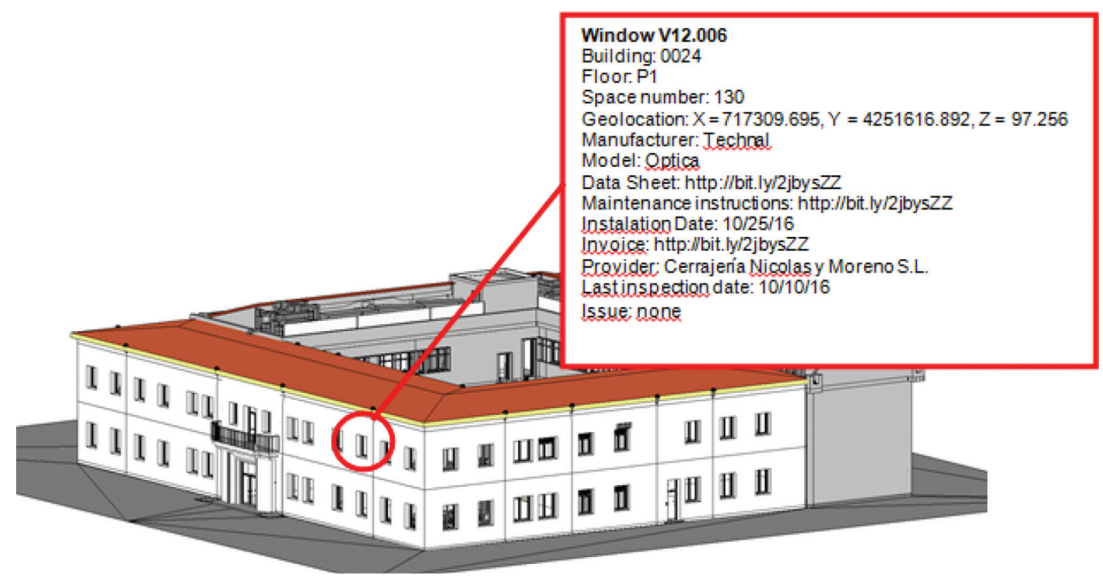

Figure 6: Data integration of the selected window.

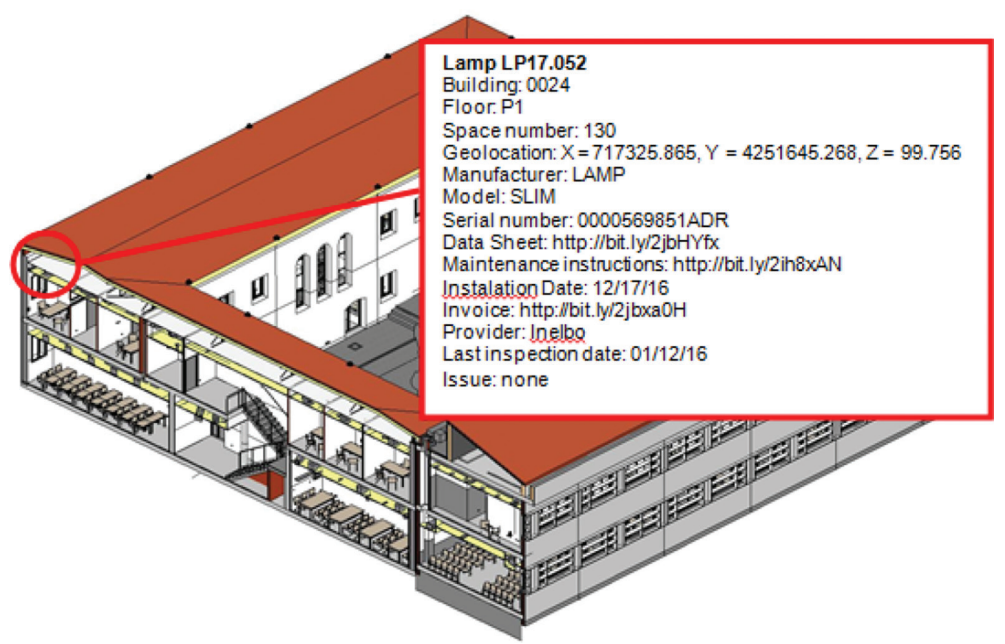

Figure 7: Data integration of the selected lamp. 


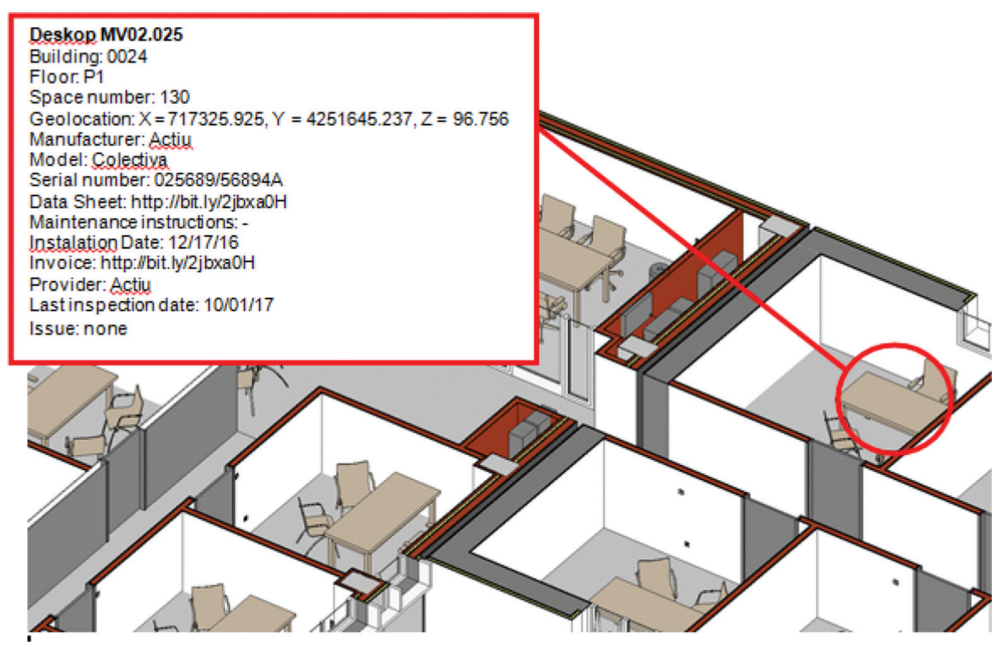

Figure 8: Data integration of the selected furniture.

For instance, if a user request a service related to a specific window, with the new and extended maintenance report, all the stakeholders can easily visualize some properties of the window like the code number, the building, the floor and the space number associated to the windows. Also its geolocation, manufacturer, model, data sheet, maintenance instructions, installation date, invoice, provider or even the last inspection date (Fig. 6)

This late information is especially relevant for the optimization and centralization of purchases. Schedule and quantities tables of providers' information are quickly and effortlessly to acquire, which facilitates to package higher quantities of deliveries. Then, better negotiations and discounts can be obtained.

Likewise, this optimization of purchases can be extrapolated to other elements like plumbing elements, furniture, or lamps, among others. Figure 7 shows the data integration of a specific lamp; this information is applicable to preventive and corrective maintenance. Again Schedule and quantities tables of installation dates, last inspection dates or Maintenance forecasts are easily available. This information can be exported to an excel sheet, and therefore, it can be achieves an efficient maintenance forecast generalized to the entire campus.

\section{CONCLUSIONS}

This research aimed to provide a theoretical framework for improving different aspects of the current maintenance process. The proposal includes the BIM paradigm together with emerging technologies such as smart sensors, personal devices and IoT's. The synergy of the elements included in the proposal will improve the efficiency of the maintenance process through the integration, standardization and centralization of computerized information, the ubiquity and accessibility to information, and the automation of some phases of the process. All this translates into efficient processes with less error-prone, more and real information for better decisions in both preventive and corrective maintenance, storage of changes and optimization of purchases.

The feasibility and potential of the proposal is validated under the BIM paradigm of the framework through the renovation model of the Former Faculty of Education building at the University of Alicante. The model shows the considerable information that can be storage and used, positioning BIM as an essential platform within the maintenance process at campus. 


\section{ACKNOWLEDGMENTS}

We gratefully acknowledge Technicians from the Technical Office and Office of the Vice President of Campus and Technology of the University of Alicante for their participation in benchmarking sessions.

\section{REFERENCES}

[1] Andújar-Montoya, M.D., Gilart-Iglesias, V., Montoyo, A. \& Marcos-Jorquera, D., A construction management framework for mass customisation in traditional construction. Sustainability, 7, pp. 5182-5210, 2015. https://doi.org/10.3390/su7055182

[2] Azhar, S., Nadeem, A., Mok, J. \& Leung, B., In Building information modeling (BIM): A new paradigm for visual interactive modeling and simulation for construction projects. Proceedings of First International Conference on Construction in Developing Countries, pp. 435-446, 2008.

[3] Succar, B., Building information modelling framework: A research and delivery foundation for industry stakeholders. Automation in Construction, 18, pp. 357-375, 2009. https://doi.org/10.1016/j.autcon.2008.10.003

[4] Azhar, S., Khalfan, M. \& Maqsood, T., Building information modeling (bim): Now and beyond. Australasian Journal of Construction Economics and Building, 12(15), 2012. https://doi.org/10.5130/ajceb.v12i4.3032

[5] Bryde, D., Broquetas, M. \& Volm, J.M., The project benefits of building information modelling (BIM). International Journal of Project Management, 31, pp. 971-980, 2013. https://doi.org/10.1016/j.ijproman.2012.12.001

[6] Miettinen, R. \& Paavola, S., Beyond the BIM utopia: Approaches to the development and implementation of building information modeling. Automation in Construction, 43, pp. 84-91, 2014. https://doi.org/10.1016/j.autcon.2014.03.009

[7] Muñoz, S., Openbim, estandarizar para afrontar los nuevos retos del mercado. BuildingSMART Spanish Chapter, 2016.

[8] Wood, B., Towards innovative building maintenance. Structural Survey, 23, pp. 291-297, 2005. https://doi.org/10.1108/02630800510630466

[9] Wang, Y., Wang, X., Wang, J., Yung, P. \& Jun, G., Engagement of facilities management in design stage through BIM: Framework and a case study. Advances in Civil Engineering, 2013, pp. 1-8, 2013. https://doi.org/10.1155/2013/189105

[10] Devetakovic, M. \& Radojevic, M., Facility management: A paradigm for expanding the scope of architectural practice. International Journal of Architectural Research: ArchNet-IJAR, 1, pp. 127-139, 2013.

[11] Akcamete, A., Akinci, B. \& Garrett, J.H., In Potential utilization of building information models for planning maintenance activities. Proceedings of the International Conference on Computing in Civil and Building Engineering, pp. 151-158, 2010.

[12] Becerik-Gerber, B., Jazizadeh, F., Li, N. \& Calis, G., Application areas and data requirements for BIM-enabled facilities management. Journal of Construction Engineering and Management, 138, pp. 431-442, 2011. https://doi.org/10.1061/(ASCE)CO.1943-7862.0000433 
[13] Migilinskas, D., Popov, V., Juocevicius, V. \& Ustinovichius, L., The benefits, obstacles and problems of practical BIM implementation. Procedia Engineering, 57, pp. 767-774, 2013. https://doi.org/10.1016/j.proeng.2013.04.097

[14] Chen, L. \& Luo, H., A BIM-based construction quality management model and its applications. Automation in Construction, 46, pp. 64-73, 2014. https://doi.org/10.1016/j.autcon.2014.05.009

[15] Bynum, P., Issa, R.R. \& Olbina, S., Building information modeling in support of sustainable design and construction. Journal of Construction Engineering and Management, 139, pp. 24-34, 2012. https://doi.org/10.1061/(ASCE)CO.1943-7862.0000560

[16] Eadie, R., Browne, M., Odeyinka, H., McKeown, C. \& McNiff, S., BIM implementation throughout the UK construction project lifecycle: an analysis. Automation in Construction, 36, pp. 145-151, 2013. https://doi.org/10.1016/j.autcon.2013.09.001

[17] Motamedi, A., Hammad, A. \& Asen, Y., Knowledge-assisted BIM-based visual analytics for failure root cause detection in facilities management. Automation in Construction, 43, pp. 73-83, 2014. https://doi.org/10.1016/j.autcon.2014.03.012

[18] Chen, H.-M. \& Wang, Y.-H., A 3-dimensional visualized approach for maintenance and management of facilities. In Proceedings of ISARC09, pp. 468-475, 2009.

[19] Liu, R. \& Issa, R., 3d visualization of sub-surface pipelines in connection with the building utilities: Integrating GIS and BIM for facility management. Computing in Civil Engineering, pp. 341-348, 2012.

[20] Lin, Y.-C. \& Su, Y.-C., Developing mobile-and BIM-based integrated visual facility maintenance management system. The Scientific World Journal, 2013. https://doi.org/10.1155/2013/124249

[21] Motawa, I. \& Almarshad, A., A knowledge-based BIM system for building maintenance. Automation in Construction, 29, pp. 173-182, 2013. https://doi.org/10.1016/j.autcon.2012.09.008

[22] Porwal, A. \& Hewage, K.N., Building information modeling (BIM) partnering framework for public construction projects. Automation in Construction, 31, pp. 204-214, 2013. https://doi.org/10.1016/j.autcon.2012.12.004 